\title{
ANALISIS KEPUASAN PETANI TERHADAP KEGIATAN PENYULUHAN PERTANIAN DI KELURAHAN KALAMPANGAN, KOTA PALANGKA RAYA KALIMANTAN TENGAH
}

\author{
Berkat* dan Revi Sunaryati**
}

\begin{abstract}
ABSTRAK
Penelitian ini bertujuan untuk mengetahui kepuasan petani di Kelurahan Kalampangan terhadap kegiatan penyuluhan pertanian, dan faktor-faktor apa saja yang mempengaruhi kepuasan petani. Kepuasan petani terhadap kegiatan penyuluhan pertanian merupakan syarat penting agar kegiatan penyuluhan pertanian berjalan secara efektif. Kepuasan pada petani akan membuat petani secara sadar dan berkemauan tinggi untuk melakukan perubahan dalam berusahatani yang memungkikan mereka mencapai keberhasilan. Penelitian ini menggunakan pendekatan kuantitatif dengan metode survei. Lokasi penelitian adalah Kelurahan Kalampangan karena merupakan sentra produksi pertanian bagi masyarakat Kota Palangka Raya. Responden penelitian adalah petani dalam kelompok tani, yang diambil sebanyak 2 orang dari setiap kelompok tani. Analisis data dengan cara deskriptif dan statistik non parametrik yaitu Korelasi Spearman.Hasil penelitian didapatkan bahwa, para petani di Kelurahan Kalampangan merupakan petani yang tergabung dalam 21 kelompok tani, dengan jumlah petani anggota mencapai 520 petani. Bidang usaha yang dikelola oleh para petani kalampangan cukup banyak dan beragam, seperti usaha pertanian (palawija, sayur-sayuran, buah-buahan), peternakan (sapi, kambing/domba, kerbau, ayam), dan perkebunan (kelapa). Tingkat kemampuan kelompok tani cukup bervariasi, mulai dari kelas pemula hingga madya, dengan sebaran terdapat sebanyak 1 kelompok kelas pemula (4,76\%), 12 kelompok kelas lanjut (57,14\%), dan 8 kelompok kelas madya (38,1\%). Data yang dikumpulkan sampel 42 petani melalui kuesioner. Maka data dianalisis dengan menggunakan statistik deskriptif dan nonparametric yang sudah Penombak dinaikkan korelasi. Hasil penelitian menunjukkan bahwa kepuasan petani tentang extesion kegiatan usaha tani telah puas kategori. Dimensi dari kualitas layanan yang nyata, keandalan, responseiveness, jaminan dan empati, adalah korelasi positif dengan kepuasan petani di desa Kalampangan, kota Palangka Raya.
\end{abstract}

Kata kunci: kepuasan, ekstensifikasi pertanian, kualitas pelayanan 


\begin{abstract}
This study aims to determine the satisfaction of farmers in Sub Kalampangan to agricultural extension activities, and the factors that influence satisfaction of farmers. Satisfaction of farmers on agricultural extension activities is an important condition for agricultural extension activities run effectively. Satisfaction of the farmers will make farmers aware of and willing to make changes in the high-farming is Where possible they achieve success. This study uses a quantitative approach with survey method. The research location is the village Kalampangan as an agricultural production center for the city of Palangkaraya. Respondents were farmers in farmer groups, taken as many as two people from each farmer group. Data were analyzed by using descriptive and non-parametric statistical correlation Spearman.Hasil research found that farmers in Sub Kalampangan are farmers who are members of 21 farmer groups, with the number of members to 520 peasant farmers. The business sectors that are managed by farmers Kalampangan are many and varied, such as agriculture (grains, vegetables, fruits), livestock (cattle, goat / sheep, buffalo, chickens) and plantations (palm). The level of ability of farmer groups is quite varied, ranging from beginner to intermediate class, with a distribution of as many as 1 group of beginners class (4.76\%), 12 advanced class group (57.14\%), and 8 groups of middle class (38.1\% ). Data collected samples of 42 farmers through questionnaires. Then the data were analyzed using descriptive statistics and nonparametric correlations that have been raised spearmen. The results showed that satisfaction extesion farmers about farming activities have been satisfied category. The dimensions of the real quality of service, reliability, responseiveness, assurance and empathy, is a positive correlation with satisfaction Kalampangan farmers in the village, the city of Palangkaraya.
\end{abstract}

Keywords: satisfaction, agricultural extension, the quality of service

\section{PENDAHULUAN}

Kelurahan Kalampangan, Kota Palangka Raya merupakan kawasan permukinan transmigran, yang dibuka sejak tahun 1982 dan masuk dalam kawasan UPT Bereng Bengkel. Pada awal dibukanya lahan pertanian di kawasan ini, usaha pertanian masih belum berkembang, berbagai permasalahan muncul sehubungan dengan kondisi lahan pertanian yang bergambut. Para petani belum mempunyai cukup pengalaman dalam mengelola lahan gambut untuk pertanian, sementara disisi lain hasupan input pertanian juga sangat tinggi sehingga rata-rata petani menghadapi kesulitan modal dalam berusahatani.

Namun sekitar dua dekade terakhir ini pertanian di Kelurahan Kalampangan, Kota Palangka Raya sudah sangat berkembang. Berbagai kegiatan usaha pertanian mulai dari tanaman palawija, hortikultura, buah- 
buahan, bahkan usaha peternakan dihasilkan oleh petani Kalampangan. Hingga kini Kelurahan Kalampangan, Kota Palangka Raya telah menjadi sentra produksi dan pensuplai utama hasil-hasil pertanian bagi masyarakat Kota Palangka Raya. Berkembangnya usaha pertanian di wilayah ini menyebabkan Pemerintahkan Kota Palangka Raya di tahun 2015 mencanangkan Kelurahan Kalampangan sebagai Kawasan Agrowisata.

Kebangkitan usaha pertanian di Kelurahan Kalampangan tersebut merupakan sebuah proses yang panjang dan ada banyak faktor yang menjadi pendorongnya. Salah satu faktor penting yang tidak kecil perannya bagi pembangunan pertanian di kelurahan ini adalah kegiatan penyuluhan pertanian. Penyuluhan pertanian yang dilakukan oleh para PPL di bawah kelembagaan BPP (Balai Penyuluhan Pertanian) Kalampangan, berjalan sejak lama seiring dengan dibukanya UPT Bereng Bengkel sebagai lokasi penampungan masyarakat transmigran berserta usaha pertanian di atasnya.

Menurut Undang-Undang Nomor 16 Tahun 2006 tentang Sistem Penyuluhan Pertanian, Perikanan dan Kehutanan (UU SP3K), arti penyuluhan pertanian adalah proses pembelajaran bagi pelaku utama serta pelaku usaha agar mereka mau dan mampu menolong dan mengorganisasikan dirinya dalam mengakses informasi pasar, teknologi, permodalan, dan sumber daya lainnya, sebagai upaya untuk meningkatkan produktivitas, efisiensi usaha, pendapatan dan kesejahteraannya serta meningkatkan kesadaran dalam pelestarian fungsi lingkungan hidup. Diungkapkan oleh Fatah (2007) masyarakat tani yang sejahtera adalah tujuan akhir yang ingin dicapai dalam penyuluhan pertanian. Hal ini baru bisa dicapai apabila petani mau dan mampu mengubah cara berusahataninya. Dengan adanya kemauan dan kemampuan mengubah cara berusaha tani ini diharapkan usahatani menjadi lebih produktif (better farming), lebih menguntungkan (better business), dan akhirnya kehidupan petani menjadi lebih baik dan layak (better living).

Penelitian ini bertujuan untuk mengetahui kepuasan petani di Kelurahan Kalampangan terhadap kegiatan penyuluhan pertanian, dan faktor-faktor apa saja yang mempengaruhi kepuasan petani. Kepuasan petani terhadap kegiatan penyuluhan pertanian merupakan syarat penting agar kegiatan penyuluhan pertanian berjalan secara efektif. Kepuasan pada petani akan membuat petani secara sadar dan berkemauan tinggi untuk melakukan perubahan dalam berusahatani yang memungkikan mereka mencapai keberhasilan.

\section{Kerangka Teoritis}

Menurut Setiana (2005), penyuluhan pertanian adalah upaya pemberdayaan petani dan nelayan beserta keluarganya melalui peningkatan pengetahuan, keterampilan, sikap, dan kemadirian agar mereka mau dan mampu, sanggup dan berswadaya memperbaiki/meningkatkan daya saing usahanya, kesejahteraan sendiri serta masyarakatnya. Pendapat lain menurut 
Samsudin (1986) dan Anwar (1988) penyuluhan pertanian adalah suatu cara atau usaha pendidikan yang bersifat nonformal bagi para petani dan keluarganya di pedesaan, yang bertujuan untuk menumbuhkan perubahan yang lebih terarah dalam kegiatan usahatani. Perubahan dimaksud adalah dalam bentuk pengetahuan, kecakapan, sikap, dan motif tindakan petani.

Bertolak dari sasaran penyuluhan adalah petani dan keluarganya, maka mereka adalah objek yang harus dikelola dengan baik agar maksud dan tujuan penyuluhan pertanian dapat tercapai. Sebagai suatu bentuk pendidikan non formal maka penyuluhan pertanian merupakan suatu bentuk pelayanan atau jasa (service) yang dimanfaatkan oleh petani dan keluarganya. Sebagai pengguna jasa penyuluhan pertanian, maka petani dan keluarganya dapat dipandang sebagai pelanggan utama yang langsung menerima manfaat atas jasa penyuluhan pertanian yang dilakukan.
Menurut Sopiatin (2010) bahwa sebelum menggunakan jasa, pelanggan dalam benaknya memiliki skenario jasa yang berbeda mengenai apa yang akan diterimanya. Pelanggan akan merasa puas apabila jasa yang diterima melampaui harapannya. Kepuasan pelanggan didefinisikan secara sederhana oleh Gaspersz (2007) dan Tjiptono (2005) sebagai suatu keadaan dimana kebutuhan, keinginan, dan harapan seseorang dapat terpenuhi melalui produk atau jasa yang diterimanya. Kotler (2000) mengungkapkan bahwa kepuasan pelanggan merupakan kepuasan terhadap sesuatu pelayanan, serta bagaimana pelayanan itu dapat memenuhi harapan pelanggan secara baik. Dalam kontek penyuluhan pertanian berarti kepuasan petani terjadi apabila mereka menerima jasa penyuluhan pertanian sesuai dengan yang mereka pikirkan atau harapkan sebelumnya.

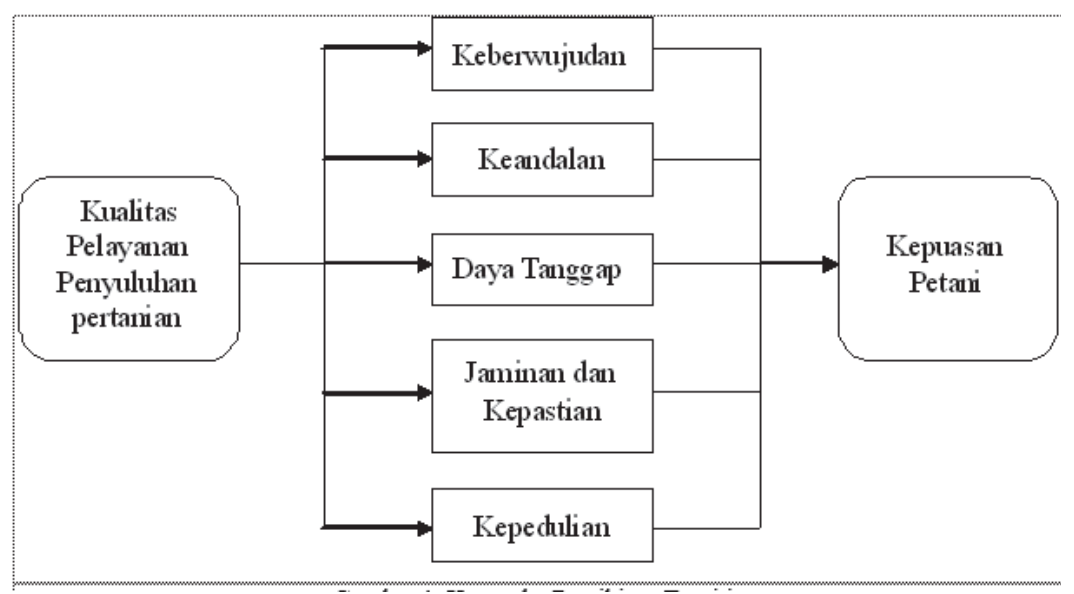

Gambar 1. Kerangka Pemikiran Teoritis 
Kepuasan petani sangat tergantung pada persepsi dan ekspektasi mereka terhadap unsur-unsur penyuluhan itu sendiri. Dalam hal ini kepuasan petani berhubungan dengan kualitas jasa penyuluhan pertanian yang dilakukan. Menurut Ariani (2009) dan Tampubolon (2001), produk dan jasa yang berkualitas adalah produk dan jasa yang sesuai dengan apa yang diinginkan oleh pelanggan. Penyuluhan pertanian merupakan sarana kebijaksanaan yang dapat digunakan pemerintah untuk mendorong pembangunan pertanian. Di lain pihak, petani mempunyai kebebasan untuk menerima atau menolak saran yang diberikan agen penyuluhan pertanian. Dengan demikian penyuluhan hanya dapat mencapai sasarannya jika perubahan yang diinginkan sesuai dengan kepentingan petani.

Pasuraman, et.al (1998), Kotler (2000), dan Tjiptono mengungkapkan lima dimensi pokok dari kualitas pelayanan, yaitu: (a) tangible/keberwujudan; (b) reliability/ keandalan; (c) responsiveness/daya tanggap; (d) assurance/jaminan dan kepastian; dan (e) empathy/kepedulian. Tangible meliputi fasilitas fisik, perlengkapan, dan peralatan yang digunakan, serta penampilan pengawainya. Reliability merupakan kemampuan untuk memberikan pelayanan sesuai dengan yang dijanjikan secara akurat dan terpercaya. Responsiveness merupakan suatu kebijakan untuk membantu dan memberikan pelayanan yang cepat (responsif) dan tepat kepada pelanggan. Assurance mencakup pengetahuan, kesopanan, dan kemampuan para staf untuk menumbuhkan rasa percaya para pelanggan. Hal ini meliputi beberapa komponen antara lain komunikasi, kredibilitas, keamanan, kompetensi, dan sopan santun. Empathy merupakan upaya memberikan perhatian yang tulus dan bersifat individual atau pribadi yang diberikan kepada para pelanggan dengan upaya memahami keinginan pelanggan.

Kualitas pelayanan penyuluhan pertanian diharapkan dapat memenuhi kebutuhan dan keinginan petani, atau dengan kata lain dapat memberikan kepuasan kepada petani. Petani yang puas dengan palayanan penyuluhan pertanian akan melakukan perubahan dalam berusahatani yang memungkikan mereka mencapai keberhasilan.

\section{METODE PENELITIAN}

Penelitian ini menggunakan pendekatan kuantitatif dengan metode survei. Lokasi penelitian adalah Kelurahan Kalampangan karena merupakan sentra produksi pertanian bagi masyarakat Kota Palangka Raya. Responden penelitian adalah petani dalam kelompok tani, yang diambil sebanyak 2 orang dari setiap kelompok tani (ketua dan anggota) dengan jumlah kelompok tani sebanyak 21 kelompok tani atau sebanyak 42 petani sampel. Pengumpulan data kualitas pelayanan penyuluhan pertanian dan kepuasan petani diambil dengan kuesioner (angket), disusun dengan skala Likert (Widoyoko, 2012) dengan rentang 1-5 (1 = sangat tidak setuju; $\quad 2=$ tidak setuju; $3=$ kurang setuju; $4=$ setuju; $5=$ sangat setuju). Analisis data dengan cara deskriptif 
dan statistik non parametrik yaitu Korelasi Spearman (Riduwan, 2009).

\section{HASIL DAN PEMBAHASAN}

Para petani di Kelurahan Kalampangan merupakan petani yang tergabung dalam 21 kelompok tani, dengan jumlah petani anggota mencapai 520 petani. Bidang usaha yang dikelola oleh para petani kalampangan cukup banyak dan beragam, seperti usaha pertanian (palawija, sayursayuran, buah-buahan), peternakan (sapi, kambing/domba, kerbau, ayam), dan perkebunan (kelapa). Tingkat kemampuan kelompok tani cukup bervariasi, mulai dari kelas pemula hingga madya, dengan sebaran terdapat sebanyak 1 kelompok kelas pemula (4,76\%), 12 kelompok kelas lanjut $(57,14 \%)$, dan 8 kelompok kelas madya $(38,1 \%)$. Jika dilihat dari kelas kelompok tani tersebut sebagian besar masih termasuk kelas lanjut (Tabel 1).

Kelurahan Kalampangan, Kota Palangka Raya merupakan kawasan sentra produksi pertanian yang menjadi salah satu wilayah kerja dari BPP Kalampangan Kota Palangka Raya. BPP Kalampangan termasuk lembaga penyuluhan pertanian yang paling lama sudah ada di Kota Palangka Raya selain BPP Tangkiling.Wilayah kerja BPP Kalampangan juga mencakup beberapa kelurahan lainnya yaitu Bereng Bengkel, Kereng Bangkirai, Sabaru, dan Danau Tundai.

Tabel 1. Klasifikasi Kelompok Tani di Kelurahan Kalampangan

\begin{tabular}{clccc}
\hline No & Kelas Kelompok Tani & Jumlah & Anggota & Bidang Usaha \\
\hline 1 & Pemula & 1 & 24 & Pertanian \\
2 & Lanjut & 12 & 293 & $\begin{array}{c}\text { Pertanian, Perkebunan, } \\
\text { Peternakan }\end{array}$ \\
3 & Madya & 8 & 203 & Pertanian, Peternakan \\
4 & Utama & 0 & 0 & - \\
\hline & Jumlah & $\mathbf{2 1}$ & $\mathbf{5 2 0}$ & - \\
\hline
\end{tabular}

Kegiatan penyuluhan pertanian di Kelurahan Kalampangan melibatkan 5 orang PPL (Penyuluh Pertanian Lapangan), 2 orang PPM (Penyuluh Pertanian Madya), dan 2 PPS (Penyuluh Pertanian Spesialis).

Hasil penilaian petani terhadap kinerja kegiatan penyuluhan pertanian sudah tergolong baik, dimana tingkat kepuasan pertani terhadap kegiatan penyuluhan pertanian sebagian besar menyatakan puas $(85,71 \%)$, dan selebihnya menyatakan sangat puas (14,29\%). Sedangkan untuk yang menyatakan kurang puas dan sangat tidak puas tidak ada $(0 \%)$. Secara lengkap tingkat kepuasan petani terhadap kinerja kegiatan penyuluhan pertanian di Kelurahan Kalampangan 
tersebut sebagaimana disajikan pada Tabel 2.

Petani Kalampangan telah mendapatkan kepuasan dari kegiatan penyuluhan pertanian yang dilakukan oleh para penyuluh pertanian. Kepuasan petani tersebut sangat terasa hasilnya dengan berkembangnya usaha pertanian di daerah ini, sehingga mampu menjadi sentra produksi pertanian bagi Kota Palangka
Raya. Hasil penelitian ini sejalan dengan pendapat Supranto (2011) yang mengungkapkan bahwa tingkat kepuasan pelanggan sangat tergantung pada kualitas produk maupun jasa atau pelayanan yang diberikan. Demikian pula dengan pendapat Kotler dan Armstrong (2008) bahwa kepuasan pelanggan sangat tergantung kepada kinerja produk terhadap ekspektasi pelanggan.

Tabel 2. Kepuasan Petani terhadap Kegiatan Penyuluhan Pertanian di Kelurahan Kalampangan

\begin{tabular}{llccc}
\hline No & \multicolumn{1}{c}{ Kriteria } & Interval & $\begin{array}{c}\text { Jumlah } \\
\text { Petani }\end{array}$ & $\begin{array}{c}\text { Persentase } \\
(\%)\end{array}$ \\
\hline 1 & Sangat Tidak Puas & $16-28$ & 0 & 0 \\
2 & Kurang Puas & $29-41$ & 0 & 0 \\
3 & Cukup Puas & $42-54$ & 0 & 0 \\
4 & Puas & $55-67$ & 36 & 85,71 \\
5 & Sangat Puas & $68-80$ & 6 & 14,29 \\
\hline & & & $\mathbf{3 0}$ & $\mathbf{1 0 0 , 0 0}$ \\
\hline
\end{tabular}

Tabel 3. Hasil Analisis Hubungan Tingkat Kepuasan Petani dengan Dimensi Kualitas Pelayanan Penyuluhan Pertanian di Kelurahan Kalampangan, Kota Palangka Raya

\begin{tabular}{llcc}
\hline No & \multicolumn{1}{c}{$\begin{array}{c}\text { Dimensi Kualitas Penyuluhan } \\
\text { Pertanian } \mathbf{X}_{\mathbf{i}}\end{array}$} & $\begin{array}{c}\text { rs } \\
\text { (rho Spearman) }\end{array}$ & Sig. (2-tailed) \\
\hline 1 & Tangible/keberwujudan $\left(\mathrm{X}_{1}\right)$ & 0,347 & $.024^{*}$ \\
2 & Reliability/keandalan $\left(\mathrm{X}_{2}\right)$ & 0,713 & $.000^{* *}$ \\
3 & Responsiveness/daya tanggap $\left(\mathrm{X}_{3}\right)$ & 0,545 & $.000^{* *}$ \\
4 & Assurance/jaminan dan kepastian $\left(\mathrm{X}_{4}\right)$ & 0,355 & $.021^{*}$ \\
5 & Empathy/kepedulian $\left(\mathrm{X}_{5}\right)$ & 0,564 & $.000^{* *}$ \\
\hline Keterangan: & & \\
$* *$ & Nyata pada taraf signifikansi 99\% & & \\
$*$ & Nyata pada taraf signifikansi $95 \%$ &
\end{tabular}


Pelanggan akan puas jika kinerjanya sesuai dengan ekspektasi pelanggan, namun jika terjadi sebaliknya maka pelanggan tidak puas. Hal ini berarti jika pelayanan penyuluhan pertanian yang diberikan oleh penyuluh berkualitas atau sesuai dengan apa yang diinginkan petani maka petani menjadi semakin puas.

Berdasarkan hasil analisis pada Tabel 3, dapat diketahui bahwa kepuasan petani terhadap kegiatan penyuluhan pertanian di Kelurahan Kalampangan, mempunyai korelasi positif dengan kualitas pelaksanaan penyuluhan pertanian. Artinya apabila petani merasa bahwa penyuluhan pertanian oleh penyuluhan berkualitas maka mereka akan merasa puas atau senang, sehingga pada akhirnya akan berdampak pada perubahan pengetahuan, kecakapan, sikap, dan motif tindakan petani untuk menjadi lebih baik dalam mengelola usahatani.Sebagaimana Tabel 3, dari ke-5 dimensi kualitas pelayanan penyuluhan pertanian yang dikaji, maka indikator yang korelasinya paling besar adalah reliability/keandalan $(\mathrm{rs}=0,713)$. Keandalan (reliability), merupakan kemampuan penyuluh untuk memberikan pelayanan sesuai dengan yang dijanjikan secara akurat dan terpercaya. Kinerja harus sesuai dengan harapan pelanggan yang berarti ketepatan waktu, pelayanan yang sama untuk semua petani tanpa kesalahan, sikap yang simpatik, dan dengan akurasi yang tinggi. Dalam hal ini dapat dikatakan kualitas pelayanan penyuluhan yang berfokus kepada ketepatan pelayanan yang terpercaya.
Dimensi yang penting juga bagi petani di Kelurahan Kalampangan adalah empathy/kepedulian ( $\mathrm{rs}=0,564)$ dan responsiveness/daya tanggap $(\mathrm{rs}=0,545)$. Empati (empathy) yaitu penyuluh memberikan perhatian yang tulus dan bersifat individual atau pribadi yang diberikan kepada para petani dengan upaya memahami keinginan petani. Daya tanggap (responsiveness) merupakan kesigapan penyuluh dalam merespon masalah yang disampaikan petani secara cepat dan tepat.

\section{KESIMPULAN DAN SARAN}

\section{Kesimpulan}

1. Kegiatan penyuluhan pertanian yang dilakukan oleh penyuluh telah memberikan kepuasan yang tinggi bagi para petani di Kelurahan Kalampangan.

2. Kualitas pelayanan penyuluhan pertanian dengan dimensi (a) tangible/ keberwujudan; (b) reliability/ keandalan; (c) responsiveness/daya tanggap; (d) assurance/jaminan dan kepastian; dan (e) empathy/kepedulian, mempunyai hubungan yang positif dengan kepuasan petani di Kelurahan Kalampangan Kota Palangka Raya.

\section{Saran}

1. Penting bagi para penyuluh untuk melayani petani secara berkualitas dengan berfokus pada ketepatan pelayanan yang terpercaya, cepat 
tanggap terhadap masalah atau keluhan para petani, dan perhatian yang tulus dalam melayani petani.

2. Penyuluhan pertanian perlu didukung pula dengan ketersediaan fasilitas fisik, perlengkapan, dan peralatan yang digunakan, serta penampilan petugas penyuluhan yang dapat memuaskan petani.

\section{DAFTAR PUSTAKA}

Anward, Yus'a. 1988. Dasar-dasar Penyuluhan Pertanian. Teori dan Aplikasi. Banjarmasin: Lambung Mangkurat Unversity Press.

Ariani, Dorothea Wahyu. 2009. Manajemen Kualitas. Jakarta: Universitas Terbuka.

Fatah, Luthfi. 2007. Dinamika Pembangunan Pertanian dan Pedesaan. Banjarbaru: Pustaka Banua.

Gaspersz, Vincent. 2007. Manajemen Kualitas. Penerapan Konsepkonsep dalam Manajemen Bisnis Total. Jakarta: Gramedia Pustaka.

Kotler, Philip, and Gary Armstrong. 2008. Principles of Marketing, 12th Edition. New Jersey: Prentice Hall.

Kotler, Philip. 2000. Marketing Management. New Jersey: Prentice Hall.

Pasuraman, Valerie A. Zeithaml, dan L.L. Berry. 1998. Servqual: A
Multiple Item Scale for Measuring Consumer Perceptions of Service. Journal of Retailing. Vo. 64. No. 1.

Riduwan. 2009. Skala Pengukuran Variabel-variabel Penelitian. Bandung: Alfabeta.

Samsudin, U. 1986. Dasar-dasar Penyuluhan dan Modernisasi Pertanian. Bandung: Binacipta.

Setiana, Lucie. 2005. Penyuluhan dan Pemberdayaan Masyarakat. Bogor: Ghalia Indonesia.

Sopiatin, Popi. 2001. Manajemen Belajar Berbasis Kepuasan. Bogor: Ghalia Indonesia.

Supranto, J. 2011. Pengukuran Tingkat Kepuasan Pelanggan Untuk Menaikkan Pangsa Pasar. Jakarta: Rineka Cipta.

Tampubolon, Daulat P. 2001. Perguruan Tinggi Bermutu. Paradigma Baru Manajemen Pendidikan Tinggi Menghadapi Tantangan Abad Ke-21. Jakarta: PT Gramedia Pustaka Utama.

Tjiptono, Fandy. 2005. Prinsip-prinsip Total Quality Service. Yogyakarta: Andi.

Undang-Undang Nomor 16 Tahun 2006 tentang Sistem Penyuluhan Pertanian, Perikanan dan Kehutanan (UU SP3K).

Widoyoko, S. Eko Putro. 2012. Teknik Penyusunan Instrumen Penelitian. Yogyakarta: Pusaka Pelajar. 
Lampiran. Hasil analis is Korelasi Non Parametrik

\begin{tabular}{|c|c|c|c|c|c|c|c|c|}
\hline \multicolumn{9}{|c|}{ Correlations } \\
\hline & & & $Y$ & $\mathrm{X} 1$ & $\times 2$ & $\times 3$ & $X_{4}$ & $\times 5$ \\
\hline \multirow[t]{18}{*}{ Spearman's rho } & $Y$ & Correlation Coefficient & 1.000 & $.347^{\prime}$ & $.713^{*}$ & $.545^{\prime \prime}$ & $.355^{\circ}$ & $.564^{\prime \prime}$ \\
\hline & & Sig. (2-tailed) & & .024 & .000 & .000 & .021 & .000 \\
\hline & & $\mathrm{N}$ & 42 & 42 & 42 & 42 & 42 & 42 \\
\hline & $\mathrm{X} 1$ & Correlation Coefficient & $.347^{\circ}$ & 1.000 & .189 & .239 & .128 & $.324^{\circ}$ \\
\hline & & Sig. (2-tailed) & .024 & & .231 & .127 & .420 & .036 \\
\hline & & $\mathrm{N}$ & 42 & 42 & 42 & 42 & 42 & 42 \\
\hline & $\times 2$ & Correlation Coefficient & $.713^{*}$ & .189 & 1.000 & $.428^{\prime \prime}$ & .297 & $.585^{\prime \prime}$ \\
\hline & & Sig. (2-tailed) & .000 & .231 & & .005 & .057 & .000 \\
\hline & & $\mathrm{N}$ & 42 & 42 & 42 & 42 & 42 & 42 \\
\hline & $\times 3$ & Correlation Coefficient & $.545^{\prime \prime}$ & .239 & $.428^{* \prime}$ & 1.000 & .210 & $.471^{\prime \prime}$ \\
\hline & & Sig. (2-tailed) & .000 & .127 & .005 & & .182 & .002 \\
\hline & & $\mathrm{N}$ & 42 & 42 & 42 & 42 & 42 & 42 \\
\hline & $x 4$ & Correlation Coefficient & $.355^{\circ}$ & .128 & .297 & .210 & 1.000 & .176 \\
\hline & & Sig. (2-tailed) & .021 & .420 & .057 & .182 & & .265 \\
\hline & & $\mathrm{N}$ & 42 & 42 & 42 & 42 & 42 & 42 \\
\hline & $\times 5$ & Correlation Coefficient & $.564^{\prime \prime}$ & $.324^{\prime}$ & $.585^{\prime \prime}$ & $.471^{\prime \prime}$ & .176 & 1.000 \\
\hline & & Sig. (2-tailed) & .000 & .036 & .000 & .002 & .265 & \\
\hline & & $\mathrm{N}$ & 42 & 42 & 42 & 42 & 42 & 42 \\
\hline
\end{tabular}

*. Correlation is significant at the 0.05 level (2-tailed).

*. Correlation is significant at the 0.01 level (2-tailed).

*, ** Dosen Program Studi Agribisnis, Fakultas Pertanian

Universitas Palangka Raya (Email: berkatpisi@yahoo.com dan revi.sunaryati@yahoo.com) 